\title{
APSS-ASJ Best Clinical Research Award: Is There a Difference between Patients' and Parents' Perception of Physical Appearance in Adolescent Idiopathic Scoliosis?
}

\author{
Chris Yin Wei Chan, Siti Mariam Abd Gani, Min Yuen Lim, Chee Kidd Chiu, Mun Keong Kwan \\ Department of Orthopaedic Surgery, National Orthopaedic Centre of Excellence for Research and Learning, Faculty of Medicine, University of Malaya, \\ Kuala Lumpur, Malaysia
}

Study Design: Prospective study.

Purpose: To compare patients' and parents' perceptions of physical attributes (PAs) of adolescent idiopathic scoliosis (AIS) patients and to report any correlations between their perceptions and Scoliosis Research Society-22r (SRS-22r) scores.

Overview of Literature: Few studies have looked into the differences between patients' and parents' perceptions of their appearance.

Methods: AIS patient-parent pairs ( $n=170)$ were recruited. The patients' and parents' perceptions of six PAs were evaluated: waist asymmetry (WA), rib hump (RH), shoulder asymmetry (SA), neck tilt, breast asymmetry (BrA), and chest prominence. These PAs were ranked, and an aggregate PA (Agg-PA) score was derived from a score assigned to the attribute ( 6 for the most important PA and 1 for the least important). The patients also completed the SRS-22r questionnaire.

Results: Ninety-nine patients $(58.2 \%)$ and 71 patients $(41.8 \%)$ had thoracic and lumbar major curves, respectively. WA was ranked first by 54 patients $(31.8 \%)$ and 50 parents $(29.4 \%)$, whereas RH was ranked first by 50 patients $(29.4 \%)$ and 38 parents $(22.4 \%)$. The overall Agg-PA scores were similar for patients and parents $(p>0.05)$. However, for thoracic major curves (TMCs) $>40^{\circ}$, a significant difference was noted between the Agg-PA scores of patients and parents for SA (3.5 \pm 1.6 vs. $4.2 \pm 1.6, p=0.041)$ and BrA (3.0 \pm 1.6 vs. $2.2 \pm 1.3, p=0.006)$. For TMCs $\angle 40^{\circ}$, a significant difference was found between the Agg-PA scores of patients and parents for WA (3.7 \pm 1.6 vs. $4.4 \pm 1.5, p=0.050)$. BrA was negatively correlated with total SRS-22r score.

Conclusions: There were no significant differences between patients and parents in their ranking of the most important PAs. For TMCs $>40^{\circ}$, there were significant differences in the Agg-PA for SA and BrA. Pantients were more concerned about BrA and parents were more concerned about SA. Patients' perception of the six PAs had weak correlation with SRS-22r scores.

Keywords: Physical appearance; Patients; Parents; Perception; Adolescent idiopathic scoliosis

This is the 2018 APSS-Asian Spine Journal Best Paper Award.

Received Jun 29, 2018; Revised Sep 13, 2018; Accepted Sep 16, 2018

Corresponding author: Mun Keong Kwan

Department of Orthopaedic Surgery, National Orthopaedic Centre of Excellence for Research and Learning, Faculty of Medicine, University of Malaya, 50603 Kuala Lumpur, Malaysia

Tel: +60-379493385, Fax: +60-379494642, E-mail: munkeong42@hotmail.com 


\section{Introduction}

Scoliosis is a three-dimensional deformity of the spine that results in rib hump (RH), waist asymmetry (WA), and shoulder asymmetry (SA), as well as breast asymmetry (BrA) in females [1-3]. These abnormal physical attributes (PAs) affect general life and health-related quality of life (HRQL) in adolescent idiopathic scoliosis (AIS) patients [4-6]. Many studies have reported that untreated AIS patients have lower self-esteem, poor self-image, and reduced participation in social life [7-11]. Suicidal ideation, worry and concern over body development, and alcohol consumption have also been reported in these patients [12]. Rinella et al. [13] reported that parents of children with AIS rated their children's body images higher than the children themselves did. Sanders et al. [14] conducted a study in 182 patients and 133 parents using the Walter Reed Visual Assessment Scale (WRVAS) instrument. This instrument consists of a set of figures representing seven body images (domains): body curve, head pelvis, rib prominence, shoulder level, flank prominence, scapula rotation, and head rib pelvis. The study found that the WRVAS scores for children's body image of patients and parents were highly correlated. The parents gave slightly lower scores to deformity of the ribs and shoulders than did the patients [14]. However, this study did not include some important PAs, such as BrA, chest prominence (CP), and neck tilt (NT). The objective of the present study was to compare patients' and parents' perceptions of physical appearance of AIS patients and to report any correlations between patients' and parents' perceptions of physical appearances and the Scoliosis Research Society-22r (SRS22r) scores.

\section{Materials and Methods}

\section{Study design}

We prospectively recruited 195 AIS patient-parent pairs for this study. The study was conducted between June 2016 and December 2016 in a single academic institution with a dedicated spinal deformity service. The study was approved by University Malaya Medical Centre ethical board (MECID. no., 20167-2622). Patients with non-idiopathic scoliosis and those who had undergone corrective or revision surgery for scoliosis were excluded from the study.
The patients and their parents were required to complete the questionnaires independently. The patients completed a questionnaire consisting of three sections. The first section of the questionnaire was the SRS-22r patient questionnaire consisting of 22 items from five domains (function, pain, self-image, mental health, and satisfaction or dissatisfaction regarding the management of their condition). Each item was scored on a scale from
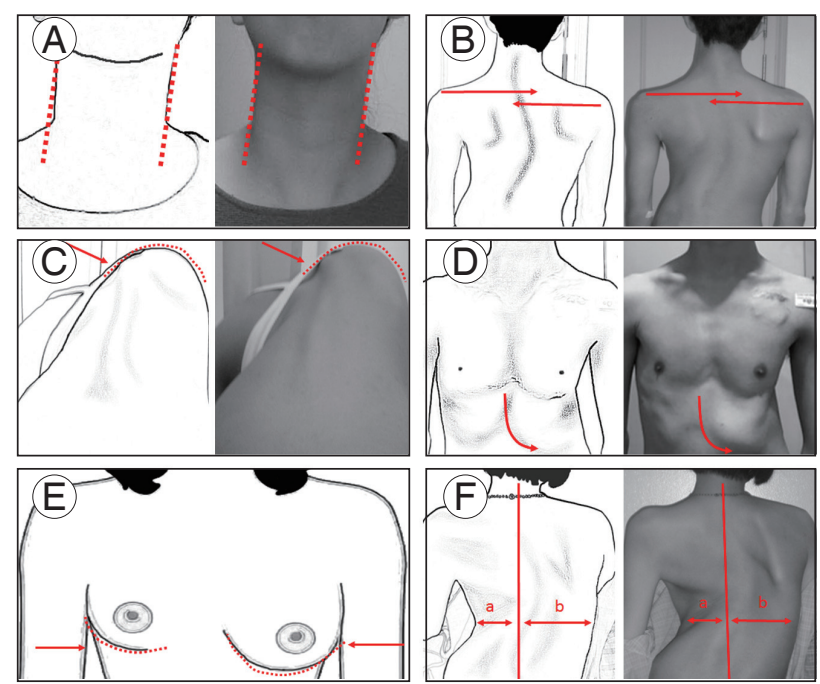

Fig. 1. PPhysical attributes: (A) neck tilt, (B) shoulder asymmetry, (C) rib hump, (D) chest prominence, (E) breast asymmetry, and (F) waist asymmetry (arrows).

Question 1: Fill in the six boxes below according to the body images above (A, B, C, D, E, and F). How do you rate your concern/worry of these body images in descending order?

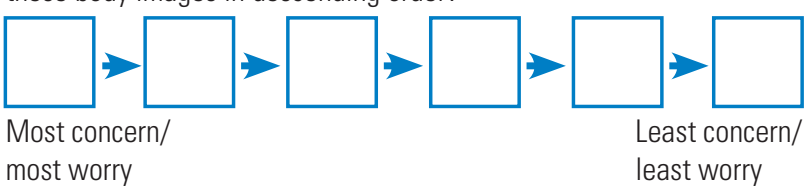

Question 1: Fill in the six boxes below according to the body images above $(A, B, C, D, E$ and $F)$. How do you rate your concern/worry of these body images in descending order?

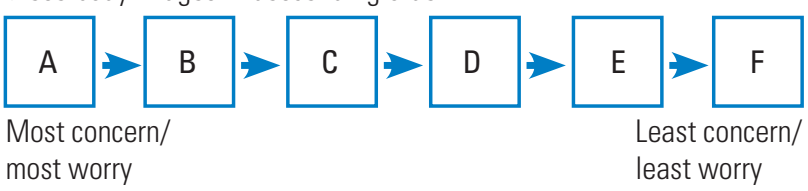

Question 1: Fill in the six boxes below according to the body images above $(A, B, C, D, E$ and $F)$. How do you rate your concern/worry of these body images in descending order?

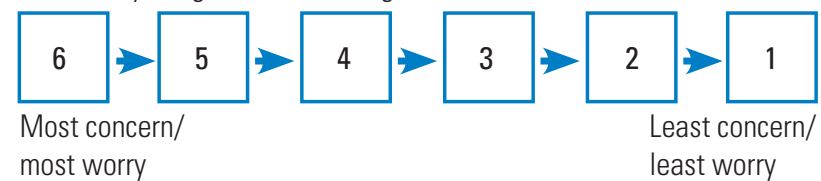

Fig. 2. Aggregate physical attribute score was generated. 
1 (worst) to 5 (best). The second section consisted of a set of figures representing six visible PAs: NT, SA, RH, CP, BrA, and WA (Fig. 1). The patients were asked to rank the PAs that concerned them the most, from the most important (scored as 6) to the least important attribute (scored as 1) (Fig. 2). This ranking was then converted into an aggregate PA (Agg-PA) score. Section 3 consisted of the patients' demographic data and clinical and radiological parameters and was completed by the investigators. The parents' questionnaire consisted of only the second section.

\section{Data collection and statistical analysis}

A total of 195 patient-parent pairs completed the questionnaire. The results from 25 pairs were excluded because of incomplete data, so that 170 patient-parent pairs were included in the data analysis. Data were collected on demographic features such as age, sex, height, and weight. Radiological data included Lenke curve classification and Cobb angle. All data were stored and analyzed with the IBM SPSS ver. 24.0 (IBM Corp., Armonk, NY, USA). Continuous data were reported as mean \pm standard deviation. The independent-samples $t$-test was used to compare the results from patients and parents, whereas the bivariate Pearson's correlation test was used to test the relationship between the Agg-PA and SRS-22r scores.

\section{Results}

There were 141 female and 29 male patients. The mean age of the patients was $15.6 \pm 4.5$ years, the mean height was $157.5 \pm 8.1 \mathrm{~cm}$, the mean weight was $46.7 \pm 9.7 \mathrm{~kg}$, and the mean Cobb angle was $43.5^{\circ} \pm 20.1^{\circ}$. There were 78 Lenke 1 patients, 15 Lenke 2 patients, four Lenke 3 patients, one Lenke 4 patient, 59 Lenke 5 patients, and 12 Lenke 6 patients (Table 1). There were 99 patients (58.2\%) with thoracic major curves and 71 patients (41.8\%) with lumbar major curves (Table 1).

WA was ranked as the most important PA by both parents and patients, followed by RH. Fifty-four patients (31.8\%) and 50 parents (29.4\%) ranked WA as the most important PA. Fifty patients (29.4\%) and 38 parents (22.4\%) ranked $\mathrm{RH}$ as the most important PA. Thirty-one patients (18.2\%) ranked CP as the most important PA,

Table 1. Demographic data of 170 patients

\begin{tabular}{lccc} 
Characteristic & Total & Thoracic & \multicolumn{1}{c}{ Lumbar } \\
No. of patients & 170 & $99(58.2)$ & $71(41.8)$ \\
Sex & & & \\
\hline \multicolumn{1}{c}{ Female } & 141 & $81(57.4)$ & $60(42.6)$ \\
\hline Male & 29 & $18(62.1)$ & $11(37.9)$ \\
\hline Age (yr) & $15.6 \pm 4.5$ & $15.7 \pm 4.9$ & $15.4 \pm 4.1$ \\
\hline Height (cm) & $157.5 \pm 8.1$ & $157.6 \pm 8.1$ & $157.3 \pm 8.2$ \\
\hline Weight (Kg) & $46.7 \pm 9.7$ & $45.2 \pm 9.0$ & $46.4 \pm 10.7$ \\
\hline Cobb angle $\left(^{\circ}\right)$ & $43.5 \pm 20.1$ & $44.2 \pm 20.5$ & $42.5 \pm 19.5$ \\
\hline Lenke classification & & & \\
\hline 1 & 78 & 78 & - \\
\hline 2 & 15 & 15 & - \\
\hline 3 & 4 & 4 & - \\
\hline 4 & 1 & 1 & - \\
\hline 5 & 59 & - & 59 \\
\hline 6 & 12 & - & 12 \\
\hline
\end{tabular}

Values are presented as number (\%) or mean \pm standard deviation.

Table 2. Most important physical attribute ranked by the patient-parent pairs

\begin{tabular}{|c|c|c|c|c|c|c|c|c|c|}
\hline \multirow{2}{*}{ Body image } & \multicolumn{3}{|c|}{ Overall } & \multicolumn{3}{|c|}{ Thoracic } & \multicolumn{3}{|c|}{ Lumbar } \\
\hline & Patient & Parent & $p$-value & Patient & Parent & $p$-value & Patient & Parent & $p$-value \\
\hline Neck tilt & $5(2.9)$ & $15(8.8)$ & 0.094 & $3(3.0)$ & 8 (8.1) & 0.263 & $2(2.8)$ & $7(7.9)$ & 0.526 \\
\hline Shoulder asymmetry & $23(13.5)$ & 33 (19.4) & & $15(15.2)$ & $22(22.2)$ & & $8(11.3)$ & $11(15.5)$ & \\
\hline Rib hump & $50(29.4)$ & $38(22.4)$ & & 37 (37.4) & $25(25.3)$ & & $13(18.3)$ & $13(18.3)$ & \\
\hline Chest prominence & $31(18.2)$ & $30(17.6)$ & & 18 (18.2) & $19(19.2)$ & & $13(18.3)$ & $11(15.5)$ & \\
\hline Breast size (asymmetry) & $7(4.1)$ & $4(2.4)$ & & $5(5.1)$ & $3(3.0)$ & & $2(2.8)$ & $1(1.4)$ & \\
\hline Waist line (asymmetry) & $54(31.8)$ & $50(29.4)$ & & $21(21.2)$ & $22(22.2)$ & & $33(46.5)$ & $28(39.4)$ & \\
\hline Total & 170 & 170 & & 99 & 99 & & 71 & 71 & \\
\hline
\end{tabular}

Values are presented as number (\%). 
and 33 parents (19.4\%) ranked SA as the most important PA. Only five patients (2.9\%) ranked NT and four parents (2.4\%) ranked $\mathrm{BrA}$ as the most important PA (Table 2).

For patients with thoracic major curves, $\mathrm{RH}$ was the most important attribute. Thirty-seven patients (37.4\%) and 25 parents $(25.3 \%)$ ranked $\mathrm{RH}$ as the most important PA. Twenty-one patients (21.2\%) ranked WA as the second most important PA. On the contrary, 22 parents (22.2\%) ranked SA and WA as the second most important attribute. Eighteen patients (18.2\%) and 19 parents (19.2\%) ranked $\mathrm{CP}$ as the most important PA. Only three patients (3.0\%) ranked $\mathrm{NT}$ as the most $\mathrm{PA}$, and only three parents (3.0\%) ranked BrA as the most important PA (Table 2).

For patients with lumbar major curves, 33 patients (46.5\%) and 28 parents (39.4\%) ranked WA as the most important PA. Thirteen patients (18.3\%) ranked RH and $\mathrm{CP}$ as the most important PA. Thirteen parents (18.3\%) ranked $\mathrm{RH}$ as the most important PA. Eleven parents (15.5\%) ranked $\mathrm{RH}$ and $\mathrm{CP}$ as the most important PA. Two patients (2.8\%) ranked NT and BrA as the most important $\mathrm{PA}$, whereas only one parent (1.4\%) ranked $\mathrm{BrA}$ as the most important PA (Table 2). Patients had significantly different perceptions of the PAs of thoracic and lumbar major curves ( $p=0.013)$, but this difference was not found in parents (Table 3 ).

For patients with lumbar major curves, WA had the highest Agg-PA scores. However, for those with thoracic major curves, RH had higher Agg-PA scores than WA in the patients' group, whereas the reverse was true in the parents' group. There were 86 patients with Cobb angle $>40^{\circ}$ (55 and 31 with thoracic and lumbar major curves, respectively) and 84 patients with Cobb angle $<40^{\circ}$ ( 44 and 40 with thoracic and lumbar major curves, respectively). Among patients with Cobb angle $>40^{\circ}$, WA and RH had the highest scores whereas BrA and NT had the lowest scores for both thoracic and lumbar major curves in the patients' and parents' groups. However, there were significant differences between patients' and parents' AggPA scores for BrA and SA (Table 4). BrA had a higher Agg-PA score among patients, whereas SA had a higher Agg-PA score among parents.

For patients with lumbar major curves with Cobb angle $<40^{\circ}$, the perceptions of patients and parents were similar regarding Agg-PA scores. WA had the highest scores, followed by RH. For patients with thoracic major curves, $\mathrm{RH}$ had the highest score among patients $(4.2 \pm 1.8)$, whereas WA had the highest score among parents $(4.4 \pm 1.5)$. Among patients, SA had the second highest score

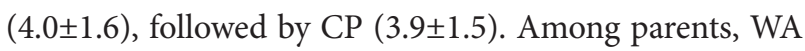
was followed by CP $(3.9 \pm 1.7)$ and SA $(3.7 \pm 1.5)$. NT and BrA had the lowest scores for both thoracic and lumbar major curves. There were no significant differences between the scores for patients and parents, but there was a trend toward statistical significance in the difference between patients and parents in the scores for WA in thoracic major curves $<40^{\circ}$ (Table 4 ).

Table 5 shows the correlation between Agg-PA scores and SRS-22r scores of patients. In the overall group analysis, $\mathrm{BrA}$ had a weak negative correlation with all the domains except for the satisfaction domain. The other significant correlations were between SA and the mental health domain, $\mathrm{CP}$ and the pain domain, and WA and the mental health domain. For patients with thoracic major curves, BrA was significantly correlated with total score,

Table 3. Most important physical attribute comparing patient and parent group

\begin{tabular}{|c|c|c|c|c|c|c|}
\hline \multirow{2}{*}{ Body image } & \multicolumn{3}{|c|}{ Patient } & \multicolumn{3}{|c|}{ Parent } \\
\hline & Thoracic & Lumbar & $p$-value & Thoracic & Lumbar & $p$-value \\
\hline Neck tilt & $3(3.0)$ & $2(2.8)$ & $0.013^{*}$ & $8(8.1)$ & $7(7.9)$ & 0.224 \\
\hline Shoulder asymmetry & $15(15.2)$ & $8(11.3)$ & & $22(22.2)$ & $11(15.5)$ & \\
\hline Rib hump & $37(37.4)$ & $13(18.3)$ & & $25(25.3)$ & $13(18.3)$ & \\
\hline Chest prominence & 18 (18.2) & $13(18.3)$ & & $19(19.2)$ & $11(15.5)$ & \\
\hline Breast size (asymmetry) & $5(5.1)$ & $2(2.8)$ & & $3(3.0)$ & $1(1.4)$ & \\
\hline Waist line (asymmetry) & $21(21.2)$ & $33(46.5)$ & & $22(22.2)$ & 28 (39.4) & \\
\hline Total & 99 & 71 & & 99 & 71 & \\
\hline
\end{tabular}

Values are presented as number (\%).

$p<0.05$ (significantly different at 0.05 ). 


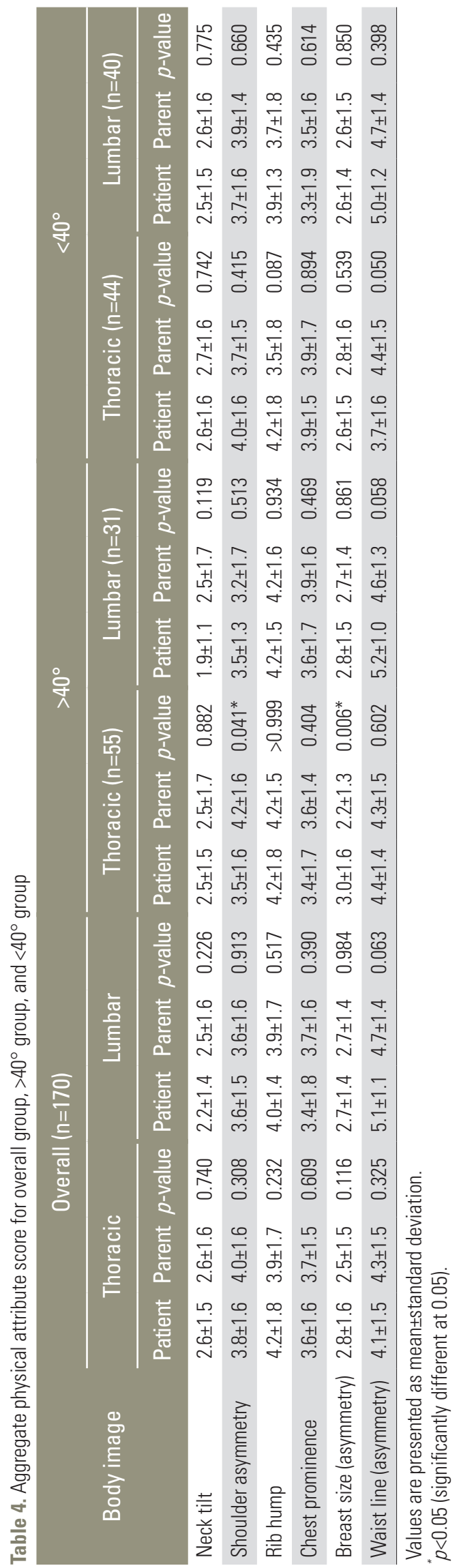

the function domain, the self-image domain, and the mental health domain. For patients with lumbar major curves, SA was significantly correlated with the mental health domain, whereas NT was significantly correlated with the satisfaction domain.

\section{Discussion}

Cosmetic correction with surgical treatment has been reported as one of the concerns of AIS patients and their families [15]. Studies have found that patients with scoliotic deformities score lower in self-image and other HRQL assessments than normal individuals. A study by Feise et al. [7] of 70 AIS patients and 14 control subjects found that AIS patients scored lower than the control group in self-esteem, mood, and feelings. Another study by Watanabe et al. [8] of 141 untreated AIS patients and 72 controls found that patients scored lower than controls in pain and self-image. A similar study by Asher et al. [16] reported that presurgical AIS patients scored lower in pain and self-image than did other study groups (braced, observed, and healthy controls). AIS patients are particularly susceptible to low self-esteem, as they are at a stage of development where they are conscious of their self-image [17-21].

In addition to patients' perceptions of their PAs, studies have been conducted on parents' perceptions and expectations about their children's body image $[6,15,22$ 24]. Failure to address the parents' concern will often lead to dissatisfied patients and dissatisfied parents following management of AIS. As reported in many studies, patients' perceptions of their body image are not always consistent with their parents' perceptions $[13,14]$. In a prospective study conducted by Rinella et al. [13], 101 operative AIS patient-parent pairs were administered the SRS-24 questionnaire at different periods of treatment. Parents consistently gave their children higher scores for selfimage, satisfaction, and total score than did the children themselves. Preoperatively, parents gave their children $7.5 \%$ higher scores for self-image than did the children themselves $(p=0.002)$. Smith et al. [24] conducted a study in 128 patients and their parents to evaluate postoperative discrepancies between the children and parents in their perceptions of the children's appearance. They found that the children rated the appearance of their waist and their overall appearance significantly worse than the parents. Fair to moderate agreement between children and parents 
Table 5. Correlation (r) table

\begin{tabular}{|c|c|c|c|c|c|c|}
\hline Physical attributes & $\begin{array}{c}\text { Total Scoliosis Research } \\
\text { Society } 22 \text { score }\end{array}$ & Function & Pain & Self image & Mental health & $\begin{array}{l}\text { Satisfaction/ } \\
\text { dissatisfaction }\end{array}$ \\
\hline \multicolumn{7}{|l|}{ Overall } \\
\hline Neck tilt & 0.140 & 0.046 & 0.061 & 0.070 & 0.150 & 0.146 \\
\hline Shoulder asymmetry & 0.131 & 0.084 & -0.039 & 0.150 & $0.191^{\text {a) }}$ & 0.073 \\
\hline Rib hump & -0.044 & -0.031 & -0.010 & -0.016 & -0.001 & -0.102 \\
\hline Chest prominence & 0.135 & 0.113 & $0.181^{\mathrm{al}}$ & 0.070 & -0.033 & 0.133 \\
\hline Breast size (asymmetry) & $-0.257^{a)}$ & $-0.184^{a)}$ & $-0.200^{\mathrm{a})}$ & $-0.206^{a)}$ & $-0.154^{a)}$ & -0.152 \\
\hline Waist line asymmetry & -0.127 & -0.045 & -0.014 & -0.084 & $-0.159^{\mathrm{a})}$ & -0.110 \\
\hline \multicolumn{7}{|l|}{ Thoracic } \\
\hline Neck tilt & 0.138 & 0.069 & 0.048 & 0.030 & $0.236^{\mathrm{a})}$ & 0.111 \\
\hline Shoulder asymmetry & 0.148 & 0.153 & 0.013 & 0.170 & 0.106 & 0.109 \\
\hline Rib hump & -0.034 & 0.037 & -0.052 & -0.032 & 0.047 & -0.134 \\
\hline Chest prominence & $0.232^{\mathrm{a})}$ & 0.148 & $0.209^{\mathrm{al}}$ & 0.138 & 0.052 & $0.257^{\text {a) }}$ \\
\hline Breast size (asymmetry) & $-0.284^{a)}$ & $-0.320^{\text {a) }}$ & -0.176 & $-0.220^{\mathrm{a})}$ & $-0.210^{\mathrm{a})}$ & -0.119 \\
\hline Waist line asymmetry & $-0.217^{\mathrm{a})}$ & -0.106 & -0.047 & -0.096 & $-0.245^{a)}$ & $-0.223^{\mathrm{a})}$ \\
\hline \multicolumn{7}{|l|}{ Lumbar } \\
\hline Neck tilt & 0.168 & 0.020 & 0.095 & 0.144 & 0.017 & $0.261^{\text {a) }}$ \\
\hline Shoulder asymmetry & 0.109 & -0.021 & -0.114 & 0.113 & $0.315^{\mathrm{al}}$ & 0.033 \\
\hline Rib hump & -0.056 & -0.151 & 0.069 & 0.019 & -0.085 & -0.029 \\
\hline Chest prominence & 0.003 & 0.073 & 0.152 & -0.036 & -0.142 & -0.016 \\
\hline Breast size (asymmetry) & -0.202 & 0.036 & -0.233 & -0.182 & -0.075 & -0.197 \\
\hline Waist line asymmetry & -0.030 & 0.028 & 0.003 & -0.064 & -0.015 & -0.055 \\
\hline
\end{tabular}

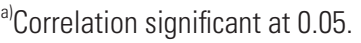

was noted for their perceptions of the appearance of the shoulder blade. The authors concluded that patients and parents do not strongly agree on the cosmetic outcome of the surgery, and patients perceive the outcome more negatively. Discrepancy between parents' and patients' perceptions should be recognized to manage their expectation of the patients' surgical or nonsurgical treatment.

Current assessment tools for PAs have been widely reported. Commonly assessed PAs include waistline asymmetry, shoulder imbalance, rib prominence, trunk shift, and CP [14,24-26]. Bago et al. [25] developed the Trunk Appearance Perception Scale to address the shortcomings of the WRVAS tool. In this assessment, three sets of figures are included showing the trunk from three viewpoints: looking toward the back, looking toward the head with the patient bending over, and looking toward the front. The patients scored the drawings on a scale from 1 (greatest deformity) to 5 (least deformity). In 2007, Sanders et al. [26] developed the Spinal Appearance Question- naire (SAQ) by incorporating the WRVAS. Additional drawings and questions on evenness of the breast, chest, waist, limb length, and shoulders and general questions about appearance, self-image, and postoperative surgical scar were asked. This tool consists of 20 items for the patient and 21 items for the parent. These PAs correlate well with HRQL scores. Asher et al. [16] conducted a prospective observational study in 119 patients and found no correlation between SRS-22r questionnaire results and curve patterns. Trunk asymmetry correlated with selfimage, and Cobb score correlated with pain, self-image, and function.

In recent years, there has been increased interest in $\mathrm{BrA}$ and NT among AIS patients [27-30]. Denoel et al. [27] conducted a study in 24 female AIS patients to describe the semiology for the assessment of BrA. In another study, Ramsay et al. [29] used MRI to characterize the presence of $\mathrm{BrA}$ in 30 female AIS patients. They reported that the left breast was larger than the right breast in 19 patients 
(65.5\%) who presented with right-sided thoracic scoliosis, whereas the right breast was larger in patients with leftsided thoracic scoliosis. Twenty patients had a BrA of $5 \%$ or greater. Concern about $\mathrm{BrA}$ among patients and parents is an important aspect to be investigated. Kwan et al. [30] prospectively assessed 89 Lenke 1 and two AIS patients and reported that NT was a different phenomenon from shoulder imbalance. In another study, Menon et al. [31] reviewed 157 operated AIS cases and found eight patients who were disappointed with their shoulder imbalance and overall appearance. These patients were further assessed to determine features determining the occurrence of shoulder imbalance.

We found good consistency between patients' and parents' perception of the PAs of scoliosis in general and in thoracic major curves and lumbar major curves. This was consistent with the results of previous studies [6,15]. Misterska et al. [6] administered the Polish version of SAQ-P1 to 41 female AIS patients and their parents. The patients ranked the deformities in order of concern from greatest to least as general, waist, shoulder, chest, curve, trunk shift, kyphosis, and prominence. The parents ranked the deformities in order of concern from greatest to least as general, waist, chest, shoulder, curve, trunk shift, kyphosis, and prominence. Overall, the patients and parents had similar concerns and perceptions of the appearance of spinal deformities. The two most concerning PAs for both patients and parents were WA and $\mathrm{RH}$. This result is consistent with the findings of Misterska et al. [6,22] and Sanders et al. [14], who reported similar findings in which head-rib-pelvic and rib prominence were scored highest.

Interestingly, there was a significant difference between patients and parents in Agg-PA scores, particularly for thoracic major curves. BrA scores were higher for patients than for parents. We also found significant correlations between BA and most of the domains in SRS-22r scores. This could be an indication that patients were aware of this important attribute and that it should be a subject of future research. NT was scored as the least important PA. This could be because this deformity is absent when the curve is less severe or has not undergone surgical intervention. Moreover, this deformity might not be apparent to patients who have long hair.

The limitations of this study include wide variation in the severity of the scoliotic deformity. Although we tried to stratify the patients according to those with Cobb angle $<40^{\circ}$ and those with Cobb angle $>40^{\circ}$, a larger sample size would be needed to understand the effect of the magnitude of Cobb angle on the perception of PAs. Our sample also consisted of a multicultural mixture of patients, which could affect their perception of the PAs. Perception of PAs in the Asian community might differ from that in Western populations.

\section{Conclusions}

In conclusion, there were no significant differences between patients and parents in their ranking of the most important PAs. Both patients and parents were most concerned about RH and WA. However, for patients with thoracic major curves $>40^{\circ}$, there were significant differences between patients and parents in their ranking of AggPA score for SA and BrA. Patients were more concerned about BrA than were parents, and parents were more concerned about SA than were patients. Patients' perception of the six PAs did not correlate strongly with SRS-22r scores.

\section{Conflict of Interest}

No potential conflict of interest relevant to this article was reported.

\section{References}

1. Auerbach JD, Lonner BS, Crerand CE, et al. Body image in patients with adolescent idiopathic scoliosis: validation of the Body Image Disturbance Questionnaire: scoliosis version. J Bone Joint Surg Am 2014;96:e61.

2. Choudhry MN, Ahmad Z, Verma R. Adolescent Idiopathic Scoliosis. Open Orthop J 2016;10:143-54.

3. Normelli H, Sevastik JA, Ljung G, Jonsson-Soderstrom AM. The symmetry of the breasts in normal and scoliotic girls. Spine (Phila Pa 1976) 1986;11:74952.

4. Asher M, Lai SM, Burton D, Manna B. The influence of spine and trunk deformity on preoperative idiopathic scoliosis patients' health-related quality of life questionnaire responses. Spine (Phila Pa 1976) 2004;29:861-8.

5. Tones M, Moss N, Polly DW Jr. A review of quality of life and psychosocial issues in scoliosis. Spine (Phila Pa 1976) 2006;31:3027-38. 
6. Misterska E, Glowacki M, Adamczyk K, Jankowski R. Patients' and parents' perceptions of appearance in scoliosis treated with a brace: a cross-sectional analysis. J Child Fam Stud 2014;23:1163-71.

7. Feise RJ, Donaldson S, Crowther ER, Menke JM, Wright JG. Construction and validation of the scoliosis quality of life index in adolescent idiopathic scoliosis. Spine (Phila Pa 1976) 2005;30:1310-5.

8. Watanabe K, Hasegawa K, Hirano T, Uchiyama S, Endo N. Use of the scoliosis research society outcomes instrument to evaluate patient outcome in untreated idiopathic scoliosis patients in Japan: part II: relation between spinal deformity and patient outcomes. Spine (Phila Pa 1976) 2005;30:1202-5.

9. Asher M, Min Lai S, Burton D, Manna B. The reliability and concurrent validity of the scoliosis research society-22 patient questionnaire for idiopathic scoliosis. Spine (Phila Pa 1976) 2003;28:63-9.

10. Freidel K, Petermann F, Reichel D, Steiner A, Warschburger P, Weiss HR. Quality of life in women with idiopathic scoliosis. Spine (Phila $\mathrm{Pa} 1976$ ) 2002;27:E87-91.

11. Weinstein SL, Dolan LA, Cheng JC, Danielsson A, Morcuende JA. Adolescent idiopathic scoliosis. Lancet 2008;371:1527-37.

12. Payne WK 3rd, Ogilvie JW, Resnick MD, Kane RL, Transfeldt EE, Blum RW. Does scoliosis have a psychological impact and does gender make a difference? Spine (Phila Pa 1976) 1997;22:1380-4.

13. Rinella A, Lenke L, Peelle M, Edwards C, Bridwell $\mathrm{KH}$, Sides B. Comparison of SRS questionnaire results submitted by both parents and patients in the operative treatment of idiopathic scoliosis. Spine (Phila Pa 1976) 2004;29:303-10.

14. Sanders JO, Polly DW Jr, Cats-Baril W, et al. Analysis of patient and parent assessment of deformity in idiopathic scoliosis using the Walter Reed Visual Assessment Scale. Spine (Phila Pa 1976) 2003;28:215863.

15. Bridwell KH, Shufflebarger HL, Lenke LG, Lowe TG, Betz RR, Bassett GS. Parents' and patients' preferences and concerns in idiopathic adolescent scoliosis: a cross-sectional preoperative analysis. Spine (Phila Pa 1976) 2000;25:2392-9.

16. Asher M, Min Lai S, Burton D, Manna B. Discrimination validity of the scoliosis research society-22 patient questionnaire: relationship to idiopathic sco- liosis curve pattern and curve size. Spine (Phila $\mathrm{Pa}$ 1976) 2003;28:74-8.

17. Carrasco MI, Ruiz MC. Perceived self-image in adolescent idiopathic scoliosis: an integrative review of the literature. Rev Esc Enferm USP 2014;48:748-58.

18. Danielsson AJ, Hasserius R, Ohlin A, Nachemson AL. Body appearance and quality of life in adult patients with adolescent idiopathic scoliosis treated with a brace or under observation alone during adolescence. Spine (Phila Pa 1976) 2012;37:755-62.

19. Kinel E, Kotwicki T, Podolska A, Bialek M, Stryla W. Quality of life and stress level in adolescents with idiopathic scoliosis subjected to conservative treatment. Stud Health Technol Inform 2012;176:419-22.

20. Misterska E, Glowacki M, Latuszewska J, Adamczyk K. Perception of stress level, trunk appearance, body function and mental health in females with adolescent idiopathic scoliosis treated conservatively: a longitudinal analysis. Qual Life Res 2013;22:1633-45.

21. Goldberg MS, Mayo NE, Poitras B, Scott S, Hanley J. The Ste-Justine Adolescent Idiopathic Scoliosis Cohort Study: part II: perception of health, self and body image, and participation in physical activities. Spine (Phila Pa 1976) 1994;19:1562-72.

22. Misterska E, Glowacki M, Latuszewska J. Female patients' and parents' assessment of deformity- and brace-related stress in the conservative treatment of adolescent idiopathic scoliosis. Spine (Phila Pa 1976) 2012;37:1218-23.

23. Kasai Y, Morishita K, Kawakita E, Kondo T, Uchida A. Pre-and postoperative psychological characteristics in mothers of patients with idiopathic scoliosis. Eur Spine J 2006;15:1103-7.

24. Smith PL, Donaldson S, Hedden D, et al. Parents' and patients' perceptions of postoperative appearance in adolescent idiopathic scoliosis. Spine (Phila Pa 1976) 2006;31:2367-74.

25. Bago J, Sanchez-Raya J, Perez-Grueso FJ, Climent JM. The Trunk Appearance Perception Scale (TAPS): a new tool to evaluate subjective impression of trunk deformity in patients with idiopathic scoliosis. Scoliosis 2010;5:6.

26. Sanders JO, Harrast JJ, Kuklo TR, et al. The Spinal Appearance Questionnaire: results of reliability, validity, and responsiveness testing in patients with idiopathic scoliosis. Spine (Phila Pa 1976) 2007;32:271922. 
27. Denoel C, Aguirre MF, Bianco G, et al. Idiopathic scoliosis and breast asymmetry. J Plast Reconstr Aesthet Surg 2009;62:1303-8.

28. Ramsay J, Seoud L, Barchi S, et al. Assessment of breast asymmetry in adolescent idiopathic scoliosis using an automated 3D body surface measurement technique. Spine Deform 2017;5:152-8.

29. Ramsay J, Joncas J, Gilbert G, et al. Is breast asymmetry present in girls with adolescent idiopathic scoliosis? Spine Deform 2014;2:374-9.
30. Kwan MK, Wong KA, Lee CK, Chan CY. Is neck tilt and shoulder imbalance the same phenomenon?: a prospective analysis of 89 adolescent idiopathic scoliosis patients (Lenke type 1 and 2). Eur Spine J 2016;25:401-8.

31. Menon KV, Pillay HM, M A, Tahasildar N, J RK. Post-operative shoulder imbalance in adolescent idiopathic scoliosis: a study of clinical photographs. Scoliosis 2015;10:31. 